\title{
Concepções dos profissionais da atenção básica à saúde acerca da abordagem da violência doméstica contra a mulher no processo de trabalho: necessidades (in)visíveis
}

Primary health care professionals' conceptions about domestic violence against women in the labor process: (in)visible necessities

Waglânia de Mendonça Faustino e Freitas', Maria Helena Barros de Oliveira², Ana Tereza Medeiros Cavalcanti da Silva ${ }^{3}$

\footnotetext{
1 Doutoranda em Saúde Pública pela Escola Nacional de Saúde Pública Sérgio Arouca da Fundação Oswaldo Cruz (ENSP. Professora Assistente IV do Departamento de Enfermagem de Saúde Pública e Psiquiatria do Centro de Ciências da Saúde, da Universidade Federal da Paraíba-DESPP/CCS/UFPB. waglaniafreitas@ensp.fiocruz.br

${ }^{2}$ Doutora em Saúde Pública pela Fundação Oswaldo Cruz (Fiocruz) - Rio de Janeiro (RJ), Brasil. Pesquisadora Titular da Fundação Oswaldo Cruz e Coordenadora do Grupo Direitos Humanos e Saúde Helena Besserman, Escola Nacional de Saúde Pública Sérgio Arouca da Fundação Oswaldo Cruz (DIHS/ENSP/Fiocruz) - Rio de Janeiro (RJ), Brasil. mhelenbarros@globo.com

${ }^{3}$ Doutora em Enfermagem pela Escola de Enfermagem da Universidade de São Paulo (USP) - São Paulo (SP), Brasil, Professora Associada IV da Universidade Federal da Paraíba - João Pessoa (PB), Brasil.

anaterezaprof@gmail.com
}

RESUMO Este texto procura analisar o conteúdo da conferência proferida pelo professor baiano Jairnilson Paim, no IX Congresso Brasileiro de Saúde Coletiva, realizado em Recife (PE), em 2009. Traz à baila discussões sobre a importância do pensamento utópico na definição de um novo paradigma no campo da pesquisa acadêmica, proposto por diversos autores, visando à práxis em favor da consolidação do Sistema Único de Saúde (SUS) e do resgate de princípios e condutas que nortearam o processo da Reforma Sanitária Brasileira (RSB), como conquistas da sociedade organizada.

PALAVRAS CHAVE: Utopia; Reforma Sanitária; Práxis, Sistema Único de Saúde.

ABSTRACT This text looks for to analyze the content of the conference pronounced for the bahian professor, Jairnilson Paim, in IX the Brazilian Congress of Collective Health, carried through in Recife (PE), in 2009. Evidences the current debate on the importance of the utopian thought in the definition of a new paradigm in the field of the academic research, considered for diverse authors, aiming at the praxis for the consolidation of the Brazilian Health System and of the rescue of principles and behaviors that had guided the process of Brazilian Sanitary Reform (RSB), as conquests of the organized society.

KEYWORDS: Utopia, Public Health Reform, Praxis, Unified Health System. 


\section{Introdução}

A categoria gênero associada à classe social e à raça contribui para a solidificação das desigualdades e para a delimitação assimétrica do espaço a ser ocupado por homens e mulheres na sociedade, com desvantagens para a mulher.

Pela lógica androcêntrica, as divisóes das coisas e das atividades seguem um esquema de pensamento baseado na oposição entre o masculino e o feminino, de modo que a divisão entre os sexos está na 'ordem das coisas' ao explicar o que é normal, natural e inevitável, agregando aos corpos e ao habitus dos agentes um reconhecimento de legitimação (BOURDIEU, 2002).

Nessa perspectiva, a opressão de gênero é constituída como um fenômeno produzido socialmente por meio de argumentos que parecem explicar biologicamente um fato que tem natureza social, de modo que as mulheres são reconhecidas como 'naturalmente', (categoria biológica) frágeis, necessitando de 'proteção' (categoria sociológica) do outro, biologicamente mais forte.

Dessa forma, a força da ordem masculina que estrutura a ordem social androcêntrica não precisa ser justificada para ser aceita. Esta força é concebida como neutra e estrutura esquemas de pensamentos objetivos no modo de agir e ser na sociedade, bem como esquemas subjetivos na forma de perceber e apreciar o mundo a partir do espaço social que cada um ocupa, constituindo-se uma 'matriz de percepçóes e apreciaçóes' presente nos espaços públicos e privado (BOURDIEU, 2002).

Entre os espaços públicos de reprodução de desigualdades, o campo da saúde compreende um lócus onde se expressam as necessidades de saúde. Neste, os processos de trabalho existem para apresentar respostas sociais a necessidades que se manifestam, na maioria das vezes, apenas como problemas de saúde, desconsiderando os aspectos sociais que os determinam.

Esses problemas de saúde geram dano físico, psicológico e riscos, entre outros aspectos, que demandam por consultas, hospitalizações, informaçôes, encaminhamentos e exames no setor saúde, sem, contudo, atenderem à concepção ampla de saúde, por terem o caráter biológico e prescritivo como central em detrimento dos determinantes sociais da doença, que geram vulnerabilidades mais relacionadas às questóes de gênero do que a fatores biológicos (BRASIL, 2004). Isso implica em um processo de cuidado que contemple a abordagem de gênero e supere o modelo técnicobiológico ancorado na história natural da doença.

Decerto, há diferenças entre problemas e necessidades de saúde. Enquanto aqueles se referem a carências, as necessidades são compreendidas 'como aquilo que precisa 'necessariamente' ser satisfeito para que um ser continue sendo um ser' (MENDES-GONÇALVES, 1992, p. 34). Neste sentido, mais do que carências, necessidades 'expressam a ideia de projeto, porquanto o trabalho humano justifica o atendimento de uma necessidade radical' (MENDES-GONÇALVES, 1992, p. 40). Esse modo de compreender as necessidades sociais de saúde revela-se mais como uma exigência da realidade do que como a opção por uma reflexão teórica, que aponta para a pertinência de estruturar conhecimentos e habilidades que conformem competências profissionais organicamente vinculadas às exigências dos novos tempos (MENDES-GONÇALVES, 1992). Isso implica considerar que as necessidades humanas são fruto do processo histórico e econômico da formação social, que geram processos de trabalho para atender tais necessidades.

Nesse enfoque, o trabalho é compreendido enquanto práxis, momento de síntese da teoria e da prática que se materializa por meio de processos, açóes concretas no cotidiano dos serviços. Trata-se de uma categoria que dá centralidade ao ser humano ao envolver a formação do ser humano social como a base da sociedade, constituída pelos aspectos econômicos, políticos e estruturais (SILVA; BARROS, 2005).

O processo de trabalho em saúde estudado por Ricardo Bruno Mendes-Gonçalves (1992, 1994) enuncia que a ideia de trabalho envolve três elementos articulados que conformam a categoria processo de trabalho: 1 ) a atividade adequada a um fim, isto é, o próprio trabalho; 2) a matéria a que se aplica o trabalho, o objeto de trabalho; e 3) os meios de trabalho, o instrumental de trabalho (MENDES-GONÇALVES, 1992).

No campo da saúde, o processo de trabalho é o pilar no qual as práticas em saúde se efetivam como práticas sociais. Nesta perspectiva, os processos de trabalho em saúde configuram um nível técnico-operacional 
para a realização de projetos político-institucionais relacionados ao sistema de saúde com fins a atender às necessidades da sociedade, sendo atravessados por conflitos e contradiçóes que afastam a possibilidade de considerá-lo como um campo neutro.

Portanto, pensar os processos de trabalho em saúde como processos políticos para atender necessidades de saúde das mulheres requer considerar a visão de mundo dos profissionais em relação às questôes de gênero, uma vez que essa posição influencia a seleção de conteúdos que orientam as práticas profissionais. No cotidiano dos serviços de atendimento à saúde da mulher, as concepções de gênero correspondem a um instrumento de trabalho: o saber que orienta e dá qualidade às práticas profissionais na atenção à mulher em situação de violência.

No sentido de analisar os avanços e limites conquistados relacionados aos processos de trabalho, pela verificação da aplicação de conteúdos da abordagem de gênero nas práticas profissionais na atenção à mulher em situação de violência, este estudo assume importância porque objetivou investigar como as concepçóes de gênero contribuem para a produção do cuidado à mulher em situação de violência de gênero no município de João Pessoa (PB).

Nesses serviços, a função social é determinada pelos princípios do Sistema Único de Saúde (SUS) e pelos fundamentos filosóficos dos direitos humanos, entre eles o princípio da dignidade humana, o qual permite a uma pessoa afirmar sua condição humana e participar plenamente da vida (PEQUENO, 2008).

Defendemos a necessidade de acionar os profissionais de saúde da atenção básica para pensarem a violência de gênero como fenômeno que gera necessidade social e não apenas como um problema de saúde, por compreendermos que as visóes de mundo dos sujeitos envolvidos no trabalho influenciam a eleição de saberes para a efetivação das práticas profissionais.

Compreendemos que a articulação das diversas áreas do saber constitui um enfoque de análise necessário à efetivação da política de saúde da mulher, por meio de práticas profissionais potentes para a transformação da atenção à saúde da mulher, situação que pode ser exequível quando se recorrer à crítica aos saberes tradicionais, que constituem um dos instrumentos de trabalho insuficientes e em desacordo com a perspectiva da atual política de saúde da mulher.

\section{Considerações teórico-metodológicas}

Elegemos o enfoque qualitativo para refletir sobre a práxis da atenção à saúde da mulher, com recorte nas concepçóes que constituem instrumentos do processo de trabalho, na atenção à mulher em situação de violência de gênero na Estratégia Saúde da Família (ESF) do município de João Pessoa (PB).

A reflexão sobre a práxis enquanto atividade concreta pela qual os sujeitos transformam a si próprios e a realidade é produto de condicionantes históricos e sociais que possibilitam a manutenção ou a transformaçâo da consciência a fim de transformar as condiçóes existentes (FREITAS, 2005). Portanto, o olhar sobre a práxis contribui para o autoquestionamento da teoria que a subsidia, por ser esta quem remete à ação e ao desafio de verificar na prática os acertos e desacertos (KONDER, 1992), bem como sua superação para alcançar uma prática ancorada nos determinantes sociais da saúde.

A eleição metodológica do processo de trabalho justifica-se pelo pressuposto de que a efetivação da política de enfrentamento à violência contra a mulher se concretiza a partir das práticas profissionais cotidianas nos serviços de saúde.

O material empírico é fruto de entrevistas semiestruturadas aplicadas a 11 profissionais (2 homens e 9 mulheres) de um serviço da ESF pertencente ao IV Distrito Sanitário de Saúde do Município de João Pessoa $\mathrm{PB})$, distribuídos entre as seguintes áreas de atuação: enfermagem, medicina, odontologia, técnica de enfermagem, agente de saúde bucal, agente comunitário de saúde, vigilante, auxiliar de farmácia, auxiliar de limpeza e apoiador matricial.

Os depoimentos extraídos das entrevistas foram analisados pela técnica de análise crítica do discurso (FIORIN, 2005), pela qual é possível identificar a visão de mundo dos sujeitos que se manifestam discursivamente no interior da sociedade, que reproduzem 
ou rompem com a ideologia dominante. Dessa forma, o discurso se materializa pela linguagem e é veiculado pelo texto, sendo ele uma construção social, e o texto, uma produção individual organizada por palavras e expressōes para veicular a visão de mundo do sujeito.

Com base nesse referencial, o primeiro momento da análise do estudo correspondeu à transcrição das entrevistas, bem como à impressão e à leitura dos textos. No segundo momento foi realizada a identificação de temas relativos aos conteúdos de gênero, a saber: naturalização da violência contra a mulher, culpabilização pela violência sofrida, estratégias profissionais para o enfrentamento da violência contra a mulher, emancipação financeira e sua relação com a violência.

Seguindo a orientação metodológica, os textos temáticos foram posteriormente decompostos e organizados em dois diferentes blocos de significados, por coincidência/divergência temática: um que sintetizou as possibilidades e outro que sintetizou os limites apresentados pelos processos de trabalho para o enfrentamento da violência doméstica contra a mulher no cenário deste estudo. Esses blocos de significado orientaram a construção da categoria empírica 'Contribuição das práticas profissionais para a emancipação ou opressão da violência contra a mulher', que foi relacionada à literatura pertinente, para ancorar as posiçóes sociais nela reveladas.

O estudo foi aprovado pelo Comitê de Ética e Pesquisa da Escola Nacional de Saúde Pública ENSP/FIOCRUZ CEP/ENSP/FIOCRUZ, sob protocolo no 261/11.

\section{Resultados e discussão}

A violência doméstica contra a mulher indica as profundas desigualdades entre os sexos e as condiçóes sociais desfavoráveis das mulheres ao longo da história. Por impactar a saúde física e mental das mulheres, a violência contra a mulher é reconhecida como uma questão de saúde pública, sendo um tema inserido na agenda da saúde, especialmente na política de saúde destinada às mulheres. A efetivação da política se realiza por meio de processos de trabalho, nos serviços públicos de saúde, entre eles a Estratégia Saúde da Família, cenário deste estudo.
No tocante ao processo de trabalho em saúde, a compreensão das práticas em saúde - meios e modos como o trabalho se efetiva - são refletidas enquanto práticas sociais, de modo que o que se efetiva no campo da saúde se reflete no campo social. As ações, instrumentos e técnicas que configuram cada uma das práticas não se situam fora da dimensão social, política, econômica, cultural e ética das sociedades. Ao contrário, as práticas em saúde são o social no campo da saúde de modo que cada. Neste contexto, os objetos do processo de trabalho sobre os quais incide a ação profissional são resultados dos recortes técnico-sociais na leitura das necessidades de saúde realizadas por cada profissional (PEDUZZI et al., 2011).

Com base nesta reflexão, as práticas em saúde englobam a complexidade da dinâmica social, por suas articulaçóes necessárias com as políticas públicas, tanto para sua organização interna como para os processos de trabalho institucionalizados - que necessitam buscar outros saberes, compartimentados e fragmentados nas diversas especialidades e ciências que intersectam com a saúde - quanto em relação a seus aspectos externos, na qualidade de mediadoras das políticas sociais que precisam oferecer respostas aos diferentes interesses político-ideológicos dos grupos sociais de uma determinada conjuntura sócio-histórica.

Neste contexto, as posições sociais veiculadas pelos discursos dos homens e mulheres trabalhadores entrevistados sobre o objeto estudado, a abordagem de gênero no saber que constitui um dos elementos do processo de trabalho na atenção à saúde da mulher em situação de violência doméstica, revelou uma práxis ancorada na explicação naturalista dos gêneros, na qual as qualidades sociais ganham status de biológicas para justificar a opressão sofrida pelas usuárias.

Ela é mais fraca. Desde que o mundo é mundo, os homens acham que as mulheres são mais fracas. Eles não vão bater em um homem! $O$ que eles querem fazer, eles fazem nas mulheres (E1).

É a dependência da mulher com aquela pessoa... Engravidam, apanham e náo querem 
denunciar... Ficam dependendo deles. Aí, só sobra pra elas (E2).

Eu acho que, em qualquer canto, você deve orientar e conscientizar essas mulheres que existe lei, muito embora elas não queiram tomar aquela providência (denúncia). Mas, pelo menos, fica consciente que tem e que vai depender da iniciativa dela (E3).

Elas apanham e no outro dia está do mesmo jeito. Então, parece que já virou normal pra elas (E6).

Violência sempre teve, sempre existiu. Hoje a gente escuta mais... Mas, não é novidade, não. Sempre teve (E7).

Umas apanham, mas não dizem que apanham, e fica difícil d'a gente detectar [...] entâo, como ajudar?(E8).

Elas preferem apanhar... Elas dizem: Eu vou apanhar e vou sair pra onde? Elas apanham e ficam porque depois elas recebem um pouco de carinho, presentes, dinheiro (E9).

Isso é muito particular da mulher [...] é muito pessoal deles. No dia que ela achar que tá demais, ela mesma pega o caminho da delegacia ou se separe! Não dá pr'a gente se envolver nisso não! (E10).

Nesses depoimentos, as concepçóes dos profissionais sobre violência doméstica contra a mulher apresentam conteúdos, proposiçóes e argumentos do modelo tradicional de atenção à mulher, que a perspectiva emancipatória pretende superar. A visão de mundo veiculada enuncia a concepção da violência contra a mulher como uma questão do âmbito privado, naturalizada pela condição do ser mulher, portanto, à parte das necessidades a serem atendidas no trabalho em saúde.

Essa visão de mundo, que elege a explicação hegemônica sobre a naturalização essencial do feminino e do masculino para justificar a opressão sofrida pelas usuárias, constitui uma espécie de ideologia que subverte a compreensão da realidade essencial do ser humano e interdita a igualdade no âmbito da diversidade. A esse discurso naturalista opóe-se o que afirma que a humanidade do ser humano é construída nas relaçóes sociais (CHAUÍ, 1985). Essa última compreensão pressupóe que os fenômenos sociais sejam produtos da ação humana e possam ser por ela transformados.

Dessa maneira, o saber que orienta os processos de trabalho no serviço investigado apresenta-se ainda limitado pela concepção de cuidado baseada na história natural da doença, o que dificulta o alcance da saúde integral da mulher, pois não considera que a violência é um fenômeno complexo, que não se limita a ações individuais. Ao contrário, por ser um fenômeno social, as práticas profissionais necessitam de ações coletivas para a garantia dos direitos humanos das mulheres e das pessoas ao seu entorno.

O caráter hegemônico veiculado nos discursos tanto dos profissionais do sexo masculino quanto do sexo feminino enunciam que a reprodução da desigualdade de gênero é veiculada independentemente do sexo e da categoria profissional (nível de instrução).

As relaçóes de poder e, portanto, as desigualdades estáo inscritas nos corpos masculinos e femininos como naturais de modo que o capital cultural no qual a identidade subjaz define, no campo social, quem será dominante e quem será dominado (BOURDIEU, 2002). Apropriados dessa visão de mundo, homens e mulheres ancorados no capital cultural inculcam e reproduzem a concepção de que a mulher é menos capaz, necessitando de proteçấo do homem.

Por outro lado, o discurso hegemônico, sem a distinção do sexo dos participantes, enuncia também que os modelos de gênero se constroem a partir da perspectiva relacional, de modo que o que se apresenta como masculino só tem sentido a partir do feminino, fazendo com que as identidades se firmem à 'medida que ocorram aproximações e afastamentos em relação ao padrão que concentra maior poder na cultura' (GOMES, 2008 p. 237). Com efeito, os referenciais de desigualdade de gênero também se reproduzem pelas mulheres, quando 
elas concebem a ordem social androcêntrica e patriarcal como sendo a ordem naturalmente aceitável.

Outro aspecto analisado nos depoimentos trata da distância entre o que está proposto na política de atenção à mulher em situação de violência e o que se efetiva no cotidiano dos serviços. Mudaram-se os serviços, mas os processos de trabalho ainda permanecem centralizados no modelo de saúde pública tradicional, cuja base é o modelo naturalista de intervenção-cura. $\mathrm{O}$ reconhecimento das desigualdades de gênero para a promoção da equidade compreende um dos desafios do SUS e uma meta a ser alcançada, de não apenas tratar agravos, mas de produzir saúde enquanto direito humano.

Concordamos com Almeida et al. (2011) sobre a efetivaçáo do processo de trabalho com potencial para superar a opressão de gênero: é necessário que o profissional tenha formação de caráter político para além da dimensão curativa do processo de trabalho, trazendo para si parte da responsabilização da transformação social da opressão de gênero. Ainda nesta seara, Paim (2012) argumenta sobre a importância de constituir sujeitos políticos com potencial para questionar a não garantia do direito à saúde, as iniquidades e as relaçóes de subordinação como construçâo social, com potencial para transformar essas questôes em luta por uma saúde de acesso universal, como almejam as mulheres em situação de violência.

Ademais, considerando entre os significados do termo política aquele que implica em um conjunto de intençōes e práticas (CHAUÍ, 2011), argumentamos que, ao plano teórico das intençóes que se anunciam como medidas de governo e de Estado, no que se refere a um novo modo de compreender as mulheres na sociedade brasileira, deve corresponder um plano concreto de açóes, que se revela nos processos de trabalho das instituições públicas de atenção à mulher.

Portanto, reconhecer as necessidades de saúde das mulheres em situação de violência é central para a organização do cuidado nos serviços e para a transformação da práxis no campo da saúde, tendo em vista que a violência contra a mulher é um fenômeno que também determina necessidades (GUEDES; SILVA; FONSECA, 2009). Isso implica em açóes que não se limitem à cura da lesão, mas compreendam a complexidade que envolve o fenômeno da violência com agravos para a saúde mental e física das mulheres, pois a ausência de sofrimento físico náo significa ausência de sofrimento (PARENTE; NASCIMENTO; VIEIRA, 2009). A não verbalização do sofrimento da mulher e a desconsideração da violência como problema de saúde pública levam mulheres usuárias a viverem anos em sofrimento por não reconhecerem na atenção básica um espaço de acolhimento para a verbalização da violência e de busca de empoderamento para superarem a opressão de gênero decorrente da violência vivida.

Tendo em vista que essa correspondência não foi encontrada nos discursos dos sujeitos, inferimos que no trabalho em saúde na atenção à mulher em situação de violência doméstica ainda predominam açóes individuais, com foco na violência como um problema do espaço privado. Contudo, identificamos um esforço dos profissionais no sentido de fazer parecer que a prática profissional procura atender a uma nova intençáo da política. Mas, essa tentativa resulta apenas em uma atualização no discurso da política tradicional, em uma tentativa de adequá-lo aos novos tempos, que, por falta de prática que lhe corresponda, constitui uma espécie de modernização conservadora, como é possível identificar nos seguintes depoimentos:

A equipe pode ajudar, e muito. Eu vejo muitos casos aqui... Vários de urgência, que os profissionais levam pra o hospital, pra delegacia (E4).

Eu acharia que deveria orientar para procurar a delegacia. Porque, assim, ninguém merece sofrer violência doméstica nos tempos de hoje. Antigamente, se admitia, mas hoje, com tanta informação, eu acho que não admite mais sofrer esse tipo de violência (E1).

Não é fácil falar da violência... Eu tento puxar alguma conversa... Tiro uma brincadeira... $O$ que elas querem é um suporte! Mas, a gente não tá preparado para lidar com essa situação [...] Muitas vezes, passam despercebidas (E5). 
O caráter prescritivo e individual da denúncia, a menor importância dada à experiência da violência pelas mulheres, informam a visão de mundo que vitimiza a mulher. Esse modo de compreender o fenômeno da violência dificulta a percepção dessa mesma violência como um problema social que gera agravos a todos que estão no entorno da mulher em situação de violência, configurando-se como um problema de saúde pública que pede outros instrumentos, novas articulaçôes intersetoriais com os serviços que compóem a rede de atenção.

A qualidade conservadora identificada nos discursos dos sujeitos, a falta do reconhecimento da violência enquanto necessidade que o trabalho em saúde deve atender denuncia a dificuldade do profissional em problematizar a violência de gênero contra a mulher a partir da desigualdade social de poder. Desse modo, o trabalho baseado, sobretudo, no saber técnico, realiza-se sem perspectivas de transformar o status quo, visto que o impacto da ação proposta não contribui para o empoderamento da categoria mulher na sociedade.

Sobre essa reflexão, Villela (2009) explica que, sendo a identidade de gênero um dos eixos de estruturação da vida humana e, portanto, dos profissionais de saúde, a incorporação da dimensão de gênero nas políticas, planos e programas é lenta, visto que uma categoria de interpretação da realidade não se traduz facilmente em ações programáticas no cotidiano dos serviços. Por conseguinte, não é bastante ter uma política de enfrentamento à violência enquanto alcance da equidade, mas é preciso tomar o gênero como categoria analítica para compreender necessidades, em especial, as necessidade das mulheres em situação de violência.

Sob esse mesmo ponto de vista, para o enfrentamento dos problemas de saúde da mulher em situação de violência doméstica, há de se considerar ações intersetoriais e transdisciplinares que contribuam para a comunicação intersetorial, para tomadas de decisóes e para açôes que impactem coletivamente nesse enfrentamento (LUCENA et al., 2012). A prática coletiva de açóes voltadas ao enfrentamento da violência favorece a construção de redes intersetoriais e vínculos entre profissionais e usuários, contribuindo, de modo efetivo, para a superação da opressão de gênero. Estudos como o desenvolvido por D'Oliveira et al. (2009) e Hanada;
D'Oliveira; Schraiber (2010) apontam para a importância de se redefinir instrumentos, materiais e saberes para o trabalho cotidiano dos profissionais na atenção básica. Estes novos instrumentos levam em consideraçâo a subjetividade da mulher frente à violência e os determinantes sociais e culturais que a amparam ou suavizam esse fenômeno.

O esforço para identificar e superar as contradições entre as intençóes da política e a sua materialização, por meio das práticas profissionais, constitui um dos desafios do processo de trabalho na atençáo à mulher em situação de violência, na perspectiva da emancipação da opressão de gênero.

A proposta política atual é um avanço para o alcance do conceito ampliado de saúde, porém, somente a intenção não é o bastante para a transformação da práxis. A promoção da saúde demanda a compreensão de saúde como um campo relacional de conhecimentos e práticas de promoção a partir do conjunto das inter-relaçóes entre seus elementos, e não como um somatório de princípios, estratégias e açôes. Neste sentido, conhecer esses elementos -teorias, referenciais, serviços e atores envolvidos na trama dessas inter-relaçóes e como eles se modificam e se reafirmam para a formação de redes intersetoriais é fundamental para o enfrentamento à violência contra a mulher enquanto problema de saúde coletiva.

Nos depoimentos há indicativos de interesse dos profissionais entrevistados em superar a perspectiva curativa presente no saber que norteia o processo de trabalho em saúde. Esse interesse indica a teleologia que o trabalho em saúde possui, ao sinalizar para a dialética entre a prática preventiva e a promoção da saúde.

Por outro lado, a promoção da saúde implica em açóes coordenadas de diferentes esferas de governo com o setor de saúde, bem como na participação de outros setores e atores sociais e da própria comunidade. A necessidade de suporte - aqui traduzida como fortalecimento da rede de atenção à mulher em situação de violência -, a não admissão em sofrer violência e o reconhecimento da falta de preparo profissional para lidar com a violência presentes nos depoimentos partem do reconhecimento da insuficiência do modelo biológico com foco na responsabilização individual para responder ao processo de sofrimento e ao consequente 
adoecimento. Essa concepção remete à ideia de compreender os fenômenos sociais e biológicos em uma relação dinâmica na qual um vai atuar no outro produzindo agravos ou potencialidades para superar a medicalização e a psicologização da violência (HANADA; D'OLIVEIRA; SCHRAIBER, 2010).

Embora tenha predominado a concepção naturalista do adoecimento na maioria dos depoimentos, essa predominância ocorreu, principalmente, quando se questionou sobre as concepçóes de gênero, sobre a violência contra a mulher, sobre $a$ atenção às necessidades ou aos problemas de saúde em decorrência do tema e sobre o impacto desse fenômeno na saúde da mulher.

A constatação dessa realidade justifica a análise sobre os desafios e as possibilidades de mudanças qualitativas dos serviços e processos de trabalho de saúde, considerando que os serviços realizam as intençóes da política por meio de práticas profissionais ou processos de trabalho estéreis/potentes para a transformação do status quo.

Sob este olhar, a prevenção e o combate à violência exigem, como política pública, o diálogo e a articulação de diferentes serviços em uma rede integrada de atenção à mulher que vive em situação de violência, bem como a resignificação das práticas profissionais a ela destinadas. Este enfoque considera que as visóes de mundo do sujeito ancoradas em referenciais de gênero influem na escolha de conceitos para a prática profissional e no modo como os profissionais concebem suas próprias identidades sociais.

No tocante à atenção à mulher vítima de violência, a escuta qualificada às mulheres em situação de violência de gênero, o acolhimento no serviço, o respeito à cidadania e a articulação entre os diferentes serviços em uma rede integrada de atençáo à mulher constituem um primeiro passo para a superação do modelo tradicional de atenção à saúde (HANADA; D'OLIVEIRA; SCHRAIBER, 2010; D'OLIVEIRA et al., 2009).

Desse modo, o trabalho em rede tem como pressuposto o conhecimento do trabalho do outro, o conhecimento do próprio trabalho, a interação dos trabalhadores e a articulação das ações a fim de promover a efetivação dos direitos humanos das mulheres. Este conhecimento permite caracterizar a política de atenção intersetorial, considerando a complexidade que caracteriza a violência como objeto de intervenção.

Outrossim, a rede básica de saúde é compreendida como 'a porta de entrada' do serviço municipal público de saúde, por meio da ESF. Isso significa que a rede básica de saúde tem, pelo menos, duas finalidades: oferecer respostas sociais aos problemas e necessidades de saúde, e constituir-se como serviço no setor terciário da economia (PAIM, 2006).

Com base nessa realidade, a rede básica comporta a compreensão de lugar social para a realização de açóes individuais e coletivas de saúde, por meio de processos de trabalho, como práticas sociais relacionadas ao atendimento de necessidades sociais em saúde decorrentes da experiência de viver cotidianamente a existência em todas as suas dimensóes - a biológica, a social etc. Entre as responsabilidades da atenção básica encontra-se a de executar açóes de saúde da mulher por meio de processos de trabalho com potencial emancipatório da opressão de gênero (BRASIL, 2001).

Para a superação do modelo clássico de atenção à saúde da mulher, a proposta do SUS incorpora um conceito de saúde ampliado, que comporta a perspectiva dos determinantes sociais da saúde, na qual o ser humano é compreendido como sujeito que se determina, também, na esfera da vida social, e cujo adoecimento é fruto da simbiose entre a dimensão social, o ambiente onde o sujeito está inserido e a dimensão biológica. Pensar essa inter-relação é reconhecer a existência das inequidades e os meios para superá-las, além de promover a saúde em seu máximo potencial.

Aplicado à atenção à mulher é eleger a compreensão da determinação histórica, social e cultural que a violência infere à vida das mulheres, no saber que subsidia o processo de trabalho, a fim de construir novas práticas e reorientar serviços para o alcance da superação da desigualdade de gênero.

Diante destas consideraçóes, verifica-se a transversalidade das questôes de gênero, enfoque que coloca as questóes de saúde da mulher como responsabilidade do Estado na qualidade de definidor de políticas públicas para seu enfrentamento e executor dessas políticas por meio de processos de trabalho nos serviços de saúde. 


\section{Considerações finais}

A violência contra a mulher é uma questão que se caracteriza como um grave problema de saúde pública, por provocar sofrimento e adoecimento, devendo ser enfrentado devido a sua magnitude e transcendência.

Nesse sentido, o campo da saúde representa um setor da atenção primordial para a superação da opressão de gênero da qual a violência contra a mulher faz parte.

Contudo, o que se configura como política pouco se reproduz no cotidiano dos processos de trabalho em saúde. Esses processos de trabalho em saúde, as intenções da política de atenção à mulher em situação de violência e as práticas efetivadas no cotidiano dos serviços seguem caminhos distintos, com aproximaçóes e distanciamentos.

As intenções políticas têm uma aproximação com os determinantes sociais do processo saúde-doença, no qual a violência contra mulher está inscrita, enquanto que as práticas que se efetivam por meio de processos de trabalho permanecem ancoradas na perspectiva doença-cura do modelo de assistência tradicional.

Nesta concepção, o campo da saúde compreende um campo social estratégico para o enfrentamento da violência, especialmente na atenção primária, por seu caráter de lugar social. Entretanto, a compreensão do enfrentamento da violência como objeto do trabalho em saúde - portanto, com uma teleologia para transformar a situação de opressão em emancipação - demanda novos instrumentos, atitudes e reflexóes dos profissionais sobre a violência contra a mulher como um problema de saúde pública a ser enfrentando, também, pelos profissionais da saúde.

A qualidade emancipatória da opressão de gênero, enquanto direito humano da mulher, ainda se apresenta na perspectiva das conquistas de direitos e de satisfações sociais de saúde ainda não alcançadas e nas práticas profissionais de saúde, especificamente nos processos de trabalho da ESF.

Dessa maneira, destacamos a importância de serem consideradas as concepçóes de gênero dos profissionais sobre a violência contra a mulher, na construção de novas formas de se fazer o trabalho a fim de superar as concepções focadas no modelo biologicista de intervenção individual.

As práticas profissionais em saúde estão transversalizadas pelas visóes de mundo dos sujeitos, nas quais se incluem as concepçóes de gênero. Logo, o processo de trabalho da ESF, que é parte da atenção primária, pode oferecer respostas sociais aos problemas e necessidades de saúde das mulheres em situação de violência, desde que, nos instrumentos, sejam consideradas a complexidade da concepção da violência doméstica contra a mulher dos profissionais e sua relação com o enfrentamento da violência; a necessidade de estabelecer articulaçóes entre setores fora da saúde, a exemplo da educação e da assistência social; e a importância de refletir sobre a noção de comunidade, entendida como sujeito coletivo de ações para a promoção da saúde.

\section{Referências}

ALMEIDA, L. R. et al. A violência de gênero na concepção dos profissionais de saúde da atenção básica. Saúde em Debate, Rio de Janeiro, v. 35, n. 90, p. 396-404, jul./set. 2011.

BOURDIEU, P. A dominação masculina. 2. ed. Rio de Janeiro: Bertrand Brasil, 2002.

BRASIL. Ministério da Saúde. Plano nacional de políticas para muIheres. Brasília: MS, 2004.

BRASIL. Ministério da Saúde. Regionalização de Assistência à saúde: aprofunda a descentralização com equidade no acesso. NOAS-
SUS 01/01. Brasília: Ministério da Saúde, 2001 (Série A Normas e Manuais Técnicos).

CHAUÍ, M. Cultura e democracia: o discurso competente e outras falas. 13. ed. Rio de Janeiro: Cortez, 2011.

CHAUÍ, M. Participando do debate sobre mulher e violência. In: CARDOSO, R.; PAOLI, M.C. (Org.). Perspectivas antropológicas da mulher n. 4, Rio de Janeiro: Zahac,1985. p. 23-62.

D'OLIVEIRA, A.F. P. L. et al. Atenção integral à saúde de mulheres em situação de violência de gênero: uma alternativa para atenção 
primária em saúde. Ciência e Saúde Coletiva, v. 14, n. 4, 2009. p. 1037-1050.

FIORIN, J. L. Elementos de análise do discurso. 13. ed. São Paulo: Contexto-Edusp, 2005.

FREITAS, M. A. S. Práxis pedagógica e professores intelectuais: refletindo as tensões e concepções da formação/prática docente. Práxis Educacional, n. 1, 2005. p. 135-150.

GOMES, R. A dimensão simbólica da violência de gênero: uma discussão introdutória, Athenea Digital, v. 14, n. 2, 2008. p. 237-243.

GUEDES, R. N.; SILVA, A. T. M. C.; FONSECA, R. M. G. S. A violência de gênero e o processo saúde doença das mulheres. Escola Anna Nery, Rio de Janeiro, v. 13, 2009. p. 625-631.

HANADA, H.; D'OLIVEIRA, A. F. P.; SCHRAIBER, L. B. Os psicólogos na rede de assistência a mulheres em situação de violência. Estudos Feministas, v. 18, n. 1, 2010. p. 33-59.

KONDER, L. O futuro da filosofia da práxis. Rio de Janeiro: Paz e Terra, 1992.

LUCENA, K. D. T. et al. A abordagem de gênero no contexto do trabalho na ESF do município de João Pessoa (PB). Saúde em Debate, Rio de Janeiro, v. 34, n. 86, jul./set. 2010. p. 456-466.

LUCENA, K. D. T. et al. Análise espacial da violência doméstica contra a mulher entre os anos de 2002 e 2005 em João Pessoa, Paraíba, Brasil. Cadernos de Saúde Pública, Rio de Janeiro, v. 28, n. 6, 2012. p. 1111-1121

MENDES-GONÇALVES, R. B. Práticas de saúde: processos de trabaIho e necessidades. São Paulo: Departamento de Medicina Preventiva da Faculdade de Medicina da USP. 1992. Mimeografado.

Tecnologia e organização social das práticas de saúde: características tecnológicas do processo de trabalho na rede estadual de Centros de Saúde de São Paulo. São Paulo: HUCITEC, 1994

PAIM, J. S. Desafios para a Saúde Coletiva no Século XXI. Salvador: EDUFBA, 2006.
Atenção primária à saúde: uma receita para todas as estações? Saúde em debate, Rio de Janeiro, v. 36, n. 94, jul./set. 2012. p. 343-347.

PARENTE, E. O.; NASCIMENTO, R. O.; VIEIRA, L. J. E. S. Enfrentamento da violência doméstica contra a mulher por um grupo de mulheres após denúncia. Estudos Feministas. v. 17. n. 2, 2009. p. 445-465.

PEDUZZI, M. et al. Trabalho em equipe na perspectiva da gerência de serviços de saúde: instrumentos para a construção da prática interprofissional. Physis: Rio de Janeiro, v. 21, n. 2, 2011.

PEQUENO, M. J. P. O fundamento dos direitos humanos. In: ZENAIDE, M. N.; GUERRA, L. F. (org.). Direitos Humanos: capacitação de educadores. v. 1, 2008. p. 23-28. Disponível em: <http://www. redhbrasil.net/documentos/bilbioteca_on_line/modulo1/2.fundamento_dos_direitos_humanos_marconi.pdf $>$. Acesso em: 14 set. 2011.

SILVA, A. T. M.; BARROS, S. O trabalho de enfermagem no Hospital Dia na perspectiva da reforma psiquiátrica em João Pessoa - Paraíba. Revista da Escola de Enfermagem da USP, São Paulo, v. 39, n. 3, 2005. p. 310-316.

VILLELA, W. V. Relações de gênero, processo saúde-doença e uma concepção de integralidade. BIS: Boletim do Instituto de Saúde, v. 48, 2009. p. 26-30. Disponível em: <http:// periodicos.ses.sp.bvs.br/scielo.php?script=sci_arttext\&pi$d=S 1518-18122009000300005 \&|n g=p t \& n r m=i s o \& t| n g=p t>$. Acesso em: 14 set. 2011.

Recebido para publicação em junho de 2013

Versão definitiva em dezembro de 2013

Suporte financeiro: CNPq, protocolo no 402349/2010-5

Conflito de interesse: inexistente 